\title{
Speaker Device
}

National Cancer Institute

\section{Source}

National Cancer Institute. Speaker Device. NCI Thesaurus. Code C50184.

A device designed to convert electrical signals to sounds that can be heard. 